\title{
Potentiodynamic Polarization Behaviour of Electroless Ni-P-W Coatings
}

\author{
Supriyo Roy and Prasanta Sahoo \\ Department of Mechanical Engineering, Jadavpur University, Kolkata 700032, India \\ Correspondence should be addressed to Prasanta Sahoo, psjume@gmail.com
}

Received 23 April 2012; Accepted 29 May 2012

Academic Editors: A. Y. El-Etre, A. A. Franco, A. Hermann, C.-H. Hsu, and A. Nahlé

Copyright () 2012 S. Roy and P. Sahoo. This is an open access article distributed under the Creative Commons Attribution License, which permits unrestricted use, distribution, and reproduction in any medium, provided the original work is properly cited.

This paper deals with the synthesis of electroless Ni-P-W coatings on mild steel substrate followed by furnace-annealing process. Corrosion behaviors of the coatings after heat treatments at various annealing temperatures are evaluated by potentiodynamic polarization test using 3.5\% sodium chloride solution. The electrochemical parameters, that is, corrosion potential and corrosion current density, are optimized for maximum corrosion resistance using Taguchi-based grey relational analysis, considering four coating parameters, namely, concentration of nickel, concentration of reducing agent, concentration of tungsten, and annealing temperature as main design factors. The optimum combination of these four design factors is obtained from the analysis. The analysis of variance reveals that the concentration of tungsten source and annealing temperature play the most important role on the corrosion performance of the coating. Effects of the operating parameters on microstructures, in terms of porosity formation, crystallization, phase transformation, grain growth, are investigated using SEM, EDX, and XRD techniques.

\section{Introduction}

The performance and lifetime of engineering components can be enhanced by applying hard coating over the surface of the components, by allowing the mechanical properties of the substrate material to be maintained while protecting them against wear, friction, or corrosion. Basically the coating acts as a barrier to the substrate material by sealing it from the environment. Among the coating processes the electroless coating process is now widely accepted by the industries due to its simplicity and enhanced properties like improved friction, wear, and anticorrosive properties. The basic hypophosphite-reduced Ni-P and borohydridereduced Ni-B coating has proved its supremacy in providing improved hardness, corrosion, and wear resistance [14]. The corrosion resistance of electroless Ni-P coating is excellent, moreover in some environments it is superior to that of pure nickel or chromium alloys due to the amorphous nature and passivity of the coating [5]. It is obvious that increasing of coating porosity decreases the corrosion resistance of the coating. The important factor that affects the coating porosity and ultimate resistance to corrosion attack is surface roughness which is influenced by mechanical preparation of the surface and electroless nickelcoating process procedure [6]. Recently, much attention is being paid towards composite electroless nickel plating. The properties of composite electroless nickel coatings are often superior to those of basic Ni-P and Ni-B [2]. The functional composite coatings with specific characteristics such as wear, corrosion resistances and/or high hardness can be produced easily by choosing suitable particulate materials. The traditional electroless composite coatings have been prepared by adding micro-meter particles to an electroless bath such as SiC, BN, PTFE, diamond [7]. Newly developed Ni-P alloy coatings have been recently reported by the introduction of a third element such as tungsten to form ternary Ni-P-W [8-11]. Published data showed that inclusion of tungsten in binary Ni-P deposit positively affects the deposition rate, composition and deposit properties such as hardness, thermal stability, wear, corrosion resistance, and melting point [10]. Compared with electroless Ni-P coatings, incorporation of a third element into Ni-P-based coating, for instance, electroless Ni-W-P coatings, significantly influences the thermal stability and crystallization behavior of the coatings by suppression of $\mathrm{Ni}_{3} \mathrm{P}$ nucleation [11]. Ni-W-P 
coatings also exhibit higher wear resistance [12]. However, the influence of the addition of $\mathrm{W}$ on corrosion resistance has been reported by various researchers. Liu et al. [13] reported that improved corrosion resistance (nondeaerated condition) was found with increasing the $\mathrm{W}$ content in electroless Ni-P matrix. It was also reported that the corrosion behavior of the electroless Ni-P plating in $0.5 \mathrm{M}$ $\mathrm{H}_{2} \mathrm{SO}_{4}$ solution was improved by addition of $\mathrm{W}$, due to the formation of protective films of $\mathrm{W}$ oxides [14]. In addition, Gao et al. [15] reported a comparative study for electroless $\mathrm{Ni}-\mathrm{P}$ and Ni-W-P coatings, when the coatings were heattreated at $300^{\circ} \mathrm{C}$ and $350^{\circ} \mathrm{C}$, respectively, to form a single$\mathrm{Ni}$ nanocrystalline structure, the coatings presented different corrosion performances. The binary Ni-P nanostructure itself was harmful to the corrosion resistance. However, the addition of a third passivation element, W, significantly improved the corrosion resistance of the alloys due to the huge amount of grain boundary diffusion paths provided by the nanostructure, which favored the formation of the dense tungsten oxide film on the surface. It was found that the annealed ternary Ni-W-P alloys had corrosion resistance higher than their amorphous counterpart. Corrosion resistance of an electroless Ni-P-W coating is a function of its chemical composition and postdeposition heat treatment. As corrosion is a deteriorating phenomenon so it is needed to optimize the chemical composition to have a better corrosive property. The studies of the corrosion behaviour of electroless nickel coating are mainly conducted through electrochemical tests, namely, potentiodynamic polarization studies and electrochemical impedance spectroscopy. The resistance of the coatings towards corrosion is evaluated on the basis of the corrosion parameters obtained from these studies, namely, corrosion potential, corrosion current density, charge transfer resistance, double-layer capacitance, corrosion rate, and so forth [16-18]. The present study deals with the evaluation of corrosion behavior of the $\mathrm{Ni}$ $\mathrm{W}-\mathrm{P}$ coating, with the help of potentiodynamic polarization tests. The Taguchi method together with grey relational analysis is employed to optimize the process parameters in order to identify the combination of parameters that induce the maximum corrosion resistant properties in the coating. Analysis of variance is employed to observe the level of significance of the factors and their interactions. Finally, validation of the result obtained through the analysis is done with the help of confirmation test. The surface morphology and composition of Ni-W-P coatings are studied with the help of scanning electron microscopy, energy dispersed Xray analysis and X-ray diffraction analysis.

\section{The Taguchi Design Methodology}

An attempt has been made in this paper to optimize the corrosion behaviour of chemically deposited Ni-P-W coating using grey-based Taguchi method [19]. The concept of the Taguchi method is to optimize process parameters to achieve high quality with low cost. This technique is widely used in the engineering domain to get the desired performance characteristics by optimizing the design parameters. Taguchi recommends the use of the loss function to measure the quality characteristic. The value of the loss function is further transformed into a statistical measure called signal-to-noise ratio. $S / N$ ratio being the ratio of mean to standard deviation can effectively consider the variation encountered in a set of trials. A larger $S / N$ ratio represents minimization of noise factor, thus a better quality characteristic and the corresponding process parameters are incentive to the variation of environmental conditions and other noise factors. Due to the increasing number of process parameters, a special design of orthogonal arrays is used in the Taguchi method to reduce large number of experiments that need to be carried out.

\section{Grey Relational Analysis}

The present problem deals with the evaluation of corrosion characteristics by measuring the electrochemical responses (corrosion current density and corrosion potential). So, this is a complex multivariate problem and cannot be handled by the Taguchi method alone, because higher $S / N$ ratio of one response may corresponds to the lower $S / N$ ratio of the other. So, multiple responses must be converted to single performance index first. This is done by grey relational analysis. The grey system theory was first proposed by Deng in 1989 [20]. If there is no information about the system, it is called a black system; if the full information is available, it is called a white system, and a system with information known partially is called a grey system. The optimization of the process is performed in the following steps.

(a) Performing the grey relational generation in which the results of the experiments are normalized in the range between 0 and 1 .

(b) Calculation of the grey relational coefficients from the normalized data to represent the correlation between the desired and actual experimental data.

(c) Calculating the grey relational grade by averaging the grey relational coefficients. The grey relational grade is treated as the overall response of the process instead of the multiple responses of friction and wear.

(d) Performing statistical analysis of variance (ANOVA) for the input parameters with the grey relational grade and find which parameter significantly affects the process performance.

(e) Selecting the optimal levels of process parameters.

(f) Conducting confirmation experiment and verifying the optimal process parameters setting.

\section{Experimental Details}

4.1. Coating Deposition. The Ni-P-W coating is deposited on mild steel (AISI 1040) specimen of size $20 \mathrm{~mm} \times$ $20 \mathrm{~mm} \times 8 \mathrm{~mm}$. Shaping, parting, and milling processes are used accordingly for the preparation of the sample. The sample is then subjected to surface-grinding process. The sample is mechanically cleaned from foreign matters and corrosion products. After that the MS sample is cleaned 
using distilled water followed by a pickling treatment with dilute $(50 \%)$ hydrochloric acid for one minute to remove any surface layer formed like rust. Then the sample is rinsed in distilled water and methanol cleaning. A large number of trial experiments are performed before deciding the bath composition.

Table 1 indicates the bath composition and the operating conditions for successful coating of Ni-P-W on the mild steel substrate. Nickel sulphate is used as the source of nickel while sodium hypophosphite is the reducing agent. Sodium tungstate solution is used as the source of tungsten ion. The bath is prepared by adding the constituents in appropriate sequence. The $\mathrm{pH}$ of the solution is maintained around 78 by continuous monitoring with a $\mathrm{pH}$ meter. The cleaned samples are activated in palladium chloride solution at a temperature of $55^{\circ} \mathrm{C}$. Activated samples are then submerged into the chemical bath, which is maintained at a temperature between $90-92^{\circ} \mathrm{C}$ with the help of a hot plate cum stirrer, attached with a temperature sensor which is also submerged in the solution. The deposition is carried out for a period of 3 hours. The range of coating thickness is found to lie around 25-30 microns. After deposition, the samples are taken out of the bath and cleaned using distilled water. After the coating the samples are heat-treated at different temperatures $\left(400^{\circ} \mathrm{C}, 500^{\circ} \mathrm{C}\right.$ and $\left.600^{\circ} \mathrm{C}\right)$ according to the design of experiment.

4.2. Design Factors and Plan of Experiment. The process parameters are those factors which are varied within a specific range to obtain an optimum combination for desired result of the responses. The present investigation considered four coating process parameters, namely, concentration of nickel source (A), concentration of reducing agent (B), concentration of tungsten source $(\mathrm{C})$, and annealing temperature (D). For each factor, three equally spaced levels are considered. The factors and their levels considered in the present study are shown in Table 2. Planning an experiment properly is very important in order to organize the experiments in a very systematic way utilizing minimum resources. The Taguchi method uses an OA (orthogonal array) to reduce the number of experiments for determining the optimal process parameters. Orthogonal arrays allow one to compute the total DOF of main and interaction effects via a minimum number of experimental trials. As it is a four-factor three-level experiment, so the total DOF considering the individual factors and their interactions is 20 . Here $\mathrm{L}_{27}$ orthogonal array is chosen as it satisfies all the DOF conditions. The orthogonal array is shown in Table 3.

4.3. Response Variables. The present study aims to analyze the potentiodynamic polarization characteristics of electroless Ni-P-W coating. Hence, the two popular responses obtained from the Tafel extrapolation method of the polarization curve, that is, corrosion potential $\left(\mathrm{E}_{\text {corr }}\right)$ and corrosion current density $\left(\mathrm{I}_{\text {corr }}\right)$, are taken as the response variables for the current study. A nobler (positive) $\mathrm{E}_{\text {corr }}$ value

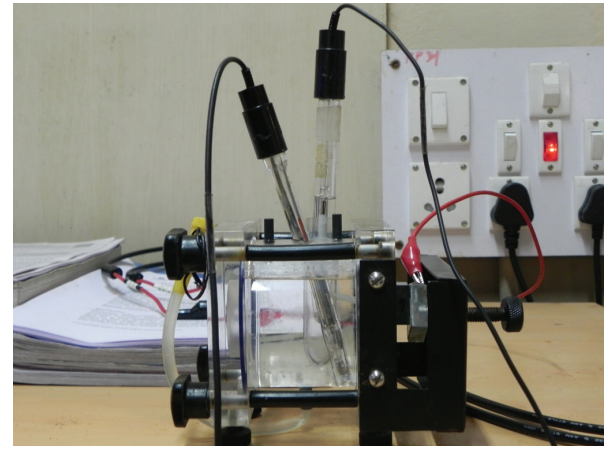

FIGURE 1: Experimental setup for potentiodynamic polarization test.

and a lower $\mathrm{I}_{\text {corr }}$ value indicate that a particular material has higher corrosion resistance.

4.4. Potentiodynamic Test. The potentiodynamic polarization tests of heat-treated Ni-P-W coatings are carried out using a potentiostat (Gill AC) of ACM Instruments, UK. The tests are conducted at an ambient temperature of about $25^{\circ} \mathrm{C}$ with $3.5 \%$ sodium chloride solution as the electrolyte. The electrochemical cell consists of three electrodes. The coated specimen forms the working electrode which is actually the sample being interrogated. A saturated calomel electrode (SCE) forms the reference electrode which provides a stable "reference" against which the applied potential may be accurately measured. A platinum electrode serves as the counter electrode which provides the path for the applied current into the solution. The design of the cell is such that only an area of $1 \mathrm{~cm}^{2}$ of the coated surface is exposed to the electrolyte. The experimental setup is shown in Figure 1. A settling time of $15 \mathrm{~min}$ is assigned before every experiment in order to stabilize the open circuit potential (OCP). The potentiostat is controlled via a PC which also captures the polarization data. The polarization plot is obtained from the dedicated software, which also possesses a special tool in order to manually extrapolate the values of $\mathrm{E}_{\text {corr }}$ (corrosion potential) and $\mathrm{I}_{\text {corr }}$ (corrosion current density) from the plot. A tafel ruler is provided with the associated software to measure the corrosion potential and the corrosion current density. Setting the horizontal ruler at the junction of anodic and cathodic branch the value of corrosion potential is measured and the corrosion current density is obtained by extrapolating the fitting lines of the anodic and cathodic branches of the tafel plot.

4.5. Microstructure Study. In order to verify the presence of nickel, phosphorous, and tungsten in the coating energy dispersive X-ray analysis (EDAX Corporation) is carried out. Scanning electron microscopy (JEOL, JSM-6360, and FEI, Quanta 200) is used to observe the surface morphology of the coating before and after heat treatment. This is done in order to analyze the effect of heat treatment on the Ni-P$\mathrm{W}$ coatings. The phases compositions before and after heat treatment are detected by using X-ray diffraction analyzer (Rigaku, Ultima III). 
TABLE 1: Electroless bath composition and operating condition.

\begin{tabular}{|c|c|c|c|}
\hline Bath constituents & Values & Operating condition & Values \\
\hline Nickel sulphate (g/L) & $20-30$ & $\mathrm{pH}$ & $7-8$ \\
\hline Sodium hypophosphite (g/L) & $14-20$ & & \\
\hline Sodium citrate $(\mathrm{g} / \mathrm{L})$ & 35 & Temperature & $90 \pm 2^{\circ} \mathrm{C}$ \\
\hline Ammonium sulphate (g/L) & 30 & Duration of coating & $3 \mathrm{hrs}$ \\
\hline Lactic acid $(\mathrm{g} / \mathrm{L})$ & 5 & & \\
\hline Sodium tungstate $(\mathrm{g} / \mathrm{L})$ & $15-25$ & Bath volume (mL) & 200 \\
\hline
\end{tabular}

TABLE 2: Design factors and their levels.

\begin{tabular}{|c|c|c|c|c|}
\hline \multirow{2}{*}{ Design factors } & \multirow{2}{*}{ Unit } & \multicolumn{3}{|c|}{ Levels } \\
\hline & & 1 & 2 & 3 \\
\hline Concentration of source of nickel (nickel sulphate solution) (A) & $\mathrm{g} / \mathrm{L}$ & 20 & $25^{\mathrm{a}}$ & 30 \\
\hline Concentration of reducing agent (sodium hypophosphite solution) (B) & $\mathrm{g} / \mathrm{L}$ & 14 & $17^{\mathrm{a}}$ & 20 \\
\hline Concentration of source of tungsten (sodium tungstate) (C) & $\mathrm{g} / \mathrm{L}$ & 15 & $20^{\mathrm{a}}$ & 25 \\
\hline Annealing temperature $(\mathrm{D})$ & ${ }^{\circ} \mathrm{C}$ & 400 & 500 & 600 \\
\hline
\end{tabular}

${ }^{a}$ Initial coating condition.

TABLE 3: L27 orthogonal array with design factors and interactions.

\begin{tabular}{|c|c|c|c|c|c|c|c|c|c|c|c|c|c|}
\hline \multirow{2}{*}{ Trial no. } & \multicolumn{13}{|c|}{ Column numbers } \\
\hline & $1(\mathrm{~A})$ & $2(\mathrm{~B})$ & $3(\mathrm{~A} \times \mathrm{B})$ & $4(\mathrm{~A} \times \mathrm{B})$ & $5(\mathrm{C})$ & $6(\mathrm{~A} \times \mathrm{C})$ & $7(\mathrm{~A} \times \mathrm{C})$ & $8(B \times C)$ & $9(\mathrm{D})$ & 10 & $11(\mathrm{~B} \times \mathrm{C})$ & 12 & 13 \\
\hline 1 & 1 & 1 & 1 & 1 & 1 & 1 & 1 & 1 & 1 & 1 & 1 & 1 & 1 \\
\hline 2 & 1 & 1 & 1 & 1 & 2 & 2 & 2 & 2 & 2 & 2 & 2 & 2 & 2 \\
\hline 3 & 1 & 1 & 1 & 1 & 3 & 3 & 3 & 3 & 3 & 3 & 3 & 3 & 3 \\
\hline 4 & 1 & 2 & 2 & 2 & 1 & 1 & 1 & 2 & 2 & 2 & 3 & 3 & 3 \\
\hline 5 & 1 & 2 & 2 & 2 & 2 & 2 & 2 & 3 & 3 & 3 & 1 & 1 & 1 \\
\hline 6 & 1 & 2 & 2 & 2 & 3 & 3 & 3 & 1 & 1 & 1 & 2 & 2 & 2 \\
\hline 7 & 1 & 3 & 3 & 3 & 1 & 1 & 1 & 3 & 3 & 3 & 2 & 2 & 2 \\
\hline 8 & 1 & 3 & 3 & 3 & 2 & 2 & 2 & 1 & 1 & 1 & 3 & 3 & 3 \\
\hline 9 & 1 & 3 & 3 & 3 & 3 & 3 & 3 & 2 & 2 & 2 & 1 & 1 & 1 \\
\hline 10 & 2 & 1 & 2 & 3 & 1 & 2 & 3 & 1 & 2 & 3 & 1 & 2 & 3 \\
\hline 11 & 2 & 1 & 2 & 3 & 2 & 3 & 1 & 2 & 3 & 1 & 2 & 3 & 1 \\
\hline 12 & 2 & 1 & 2 & 3 & 3 & 1 & 2 & 3 & 1 & 2 & 3 & 1 & 2 \\
\hline 13 & 2 & 2 & 3 & 1 & 1 & 2 & 3 & 2 & 3 & 1 & 3 & 1 & 2 \\
\hline 14 & 2 & 2 & 3 & 1 & 2 & 3 & 1 & 3 & 1 & 2 & 1 & 2 & 3 \\
\hline 15 & 2 & 2 & 3 & 1 & 3 & 1 & 2 & 1 & 2 & 3 & 2 & 3 & 1 \\
\hline 16 & 2 & 3 & 1 & 2 & 1 & 2 & 3 & 3 & 1 & 2 & 2 & 3 & 1 \\
\hline 17 & 2 & 3 & 1 & 2 & 2 & 3 & 1 & 1 & 2 & 3 & 3 & 1 & 2 \\
\hline 18 & 2 & 3 & 1 & 2 & 3 & 1 & 2 & 2 & 3 & 1 & 1 & 2 & 3 \\
\hline 19 & 3 & 1 & 3 & 2 & 1 & 3 & 2 & 1 & 3 & 2 & 1 & 3 & 2 \\
\hline 20 & 3 & 1 & 3 & 2 & 2 & 1 & 3 & 2 & 1 & 3 & 2 & 1 & 3 \\
\hline 21 & 3 & 1 & 3 & 2 & 3 & 2 & 1 & 3 & 2 & 1 & 3 & 2 & 1 \\
\hline 22 & 3 & 2 & 1 & 3 & 1 & 3 & 2 & 2 & 1 & 3 & 3 & 2 & 1 \\
\hline 23 & 3 & 2 & 1 & 3 & 2 & 1 & 3 & 3 & 2 & 1 & 1 & 3 & 2 \\
\hline 24 & 3 & 2 & 1 & 3 & 3 & 2 & 1 & 1 & 3 & 2 & 2 & 1 & 3 \\
\hline 25 & 3 & 3 & 2 & 1 & 1 & 3 & 2 & 3 & 2 & 1 & 2 & 1 & 3 \\
\hline 26 & 3 & 3 & 2 & 1 & 2 & 1 & 3 & 1 & 3 & 2 & 3 & 2 & 1 \\
\hline 27 & 3 & 3 & 2 & 1 & 3 & 2 & 1 & 2 & 1 & 3 & 1 & 3 & 2 \\
\hline
\end{tabular}


TABLE 4: Experimental results of potentiodynamic polarization test.

\begin{tabular}{|c|c|c|}
\hline Sl. no. & $\mathrm{E}_{\text {corr }}(\mathrm{mV}$ versus SCE $)$ & $\mathrm{I}_{\text {corr }}\left(\mu \mathrm{A} / \mathrm{cm}^{2}\right)$ \\
\hline 1 & -451.41 & 6.107 \\
\hline 2 & -327.02 & 0.050 \\
\hline 3 & -358.33 & 0.042 \\
\hline 4 & -468.92 & 1.967 \\
\hline 5 & -257.34 & 0.065 \\
\hline 6 & -343.07 & 0.083 \\
\hline 7 & -334.05 & 0.039 \\
\hline 8 & -330.62 & 0.071 \\
\hline 9 & -364.45 & 0.197 \\
\hline 10 & -477.13 & 4.502 \\
\hline 11 & -463.15 & 0.295 \\
\hline 12 & -336.3 & 0.256 \\
\hline 13 & -434.62 & 0.173 \\
\hline 14 & -355.74 & 0.648 \\
\hline 15 & -273.61 & 0.038 \\
\hline 16 & -408.09 & 2.479 \\
\hline 17 & -308.4 & 0.128 \\
\hline 18 & -307.84 & 0.065 \\
\hline 19 & -278.71 & 0.080 \\
\hline 20 & -388.78 & 0.485 \\
\hline 21 & -299.43 & 1.591 \\
\hline 22 & -366.32 & 0.687 \\
\hline 23 & -492.59 & 1.426 \\
\hline 24 & -304.76 & 0.062 \\
\hline 25 & -344.22 & 0.751 \\
\hline 26 & -360.3 & 0.055 \\
\hline 27 & -362.39 & 0.407 \\
\hline
\end{tabular}

\section{Results and Discussion}

5.1. Grey Analysis. Grey analysis is a method which converts the multivariate problem in to a single response problem. As the present investigation deals with two responses, namely, corrosion potential and corrosion current density, so grey analysis is employed to make it a single-response. The experimental values of corrosion potential $\left(\mathrm{E}_{\mathrm{corr}}\right)$ and corrosion current density $\left(\mathrm{I}_{\text {corr }}\right.$ ) obtained from the potentiodynamic tests are given in Table 4 . To convert the multiple responses into a single-performance index called grey relational grade, following set of calculations has been performed.

5.1.1. Normalization of Responses. The first step for generating the grey relational coefficient involves the linear normalization of the experimental results $\left(\mathrm{E}_{\text {corr }}\right.$ and $\left.\mathrm{I}_{\text {corr }}\right)$ in the range between 0 and 1 . A material will have lower tendency to corrode if the $\mathrm{E}_{\text {corr }}$ value tends to be positive with a lower value of corrosion current density. As from Table 4 it can be seen that the $\mathrm{E}_{\text {corr }}$ value is always negative, so higher the better criterion for $\mathrm{E}_{\text {corr }}$ and lower the better criterion for the $\mathrm{I}_{\text {corr }}$ is used for normalization.
Expression for higher the better:

$$
x_{i}(k)=\frac{y_{i}(k)-\min y_{i}(k)}{\max y_{i}(k)-\min y_{i}(k)} .
$$

Expression for lower the better:

$$
x_{i}(k)=\frac{\max y_{i}(k)-y_{i}(k)}{\max y_{i}(k)-\min y_{i}(k)},
$$

where $x_{i}(k)$ is the value after grey relational generation while $\min y_{i}(k)$ and $\max y_{i}(k)$ are, respectively, the smallest and largest values of $y_{i}(k)$ for the $k_{\text {th }}$ response. The data after grey relational generation is shown in Table 5 .

5.1.2. Generation of Grey Relational Coefficient. From the normalized value the grey relational coefficient is calculated by applying the equation:

$$
\xi_{i}(k)=\frac{\Delta_{\min }+\xi \Delta_{\max }}{\Delta_{o i}(k)+\xi \Delta_{\max }},
$$

where $\Delta_{o i}=\left\|x_{o}(k)-x_{i}(k)\right\|$ is the difference of the absolute value between $x_{0}(k)$ and $x_{i}(k), \Delta_{\min }$ and $\Delta_{\max }$ are, respectively, the minimum and maximum values of the absolute differences $\left(\Delta_{0 i}\right)$ of all comparing sequences. The grey relational coefficients are calculated for the experimental data using $\xi=0.5$. The values are shown in Table 5 .

5.1.3. Generation of Grey Relational Grade. The overall multiple response characteristics evaluation is based on grey relational grade which is calculated as follows:

$$
\gamma_{i}=\frac{1}{n} \sum_{k=i}^{n} \xi_{i}(k)
$$

where $n$ is the number of process responses. Finally the grades are considered for the optimization of multiresponse parameter design problem. The value of grey relational grade is shown in Table 6.

5.2. Analysis of $S / N$ Ratio. Taguchi method is used to optimize process parameters to achieve high quality with low cost. Taguchi recommends the use of the loss function to measure the quality characteristic. The value of the loss function is further transformed into a statistical measure called signal-to-noise ratio, where signal means desirable value (mean) and the noise is the undesirable value (SD). A larger $S / N$ ratio represents a better quality characteristic because of the minimization of noise and the corresponding process parameters are incentive to the variation of environmental conditions and other noise factors. The variability can be easily captured if $S / N$ ratio is used to convert the experimental results into a value for the evaluation characteristic in the optimum parameter analysis, instead of the mean. The idea is to maximize the $S / N$ ratio, thereby minimizing the effect of random noise factors, which have a significant impact on the process performance. As the grey 
TABLE 5: Grey relational analyses for corrosion potential and corrosion current density.

\begin{tabular}{|c|c|c|c|c|c|c|}
\hline \multirow{2}{*}{ Sl. no. } & \multicolumn{2}{|c|}{ Normalized value } & \multicolumn{2}{|c|}{$\Delta$ value } & \multicolumn{2}{|c|}{ Grey coefficient } \\
\hline & $\mathrm{E}_{\text {corr }}$ & $\mathrm{I}_{\text {corr }}$ & $\mathrm{E}_{\text {corr }}$ & $\mathrm{I}_{\text {corr }}$ & $\mathrm{E}_{\text {corr }}$ & $\mathrm{I}_{\text {corr }}$ \\
\hline 1 & 0.17505 & 0.00000 & 0.82495 & 1.00000 & 0.37737 & 0.33333 \\
\hline 2 & 0.70380 & 0.99804 & 0.29620 & 0.00196 & 0.62799 & 0.99609 \\
\hline 3 & 0.57071 & 0.99938 & 0.42929 & 0.00062 & 0.53805 & 0.99877 \\
\hline 4 & 0.10062 & 0.68224 & 0.89938 & 0.31776 & 0.35730 & 0.61142 \\
\hline 5 & 1.00000 & 0.99555 & 0.00000 & 0.00445 & 1.00000 & 0.99117 \\
\hline 6 & 0.63558 & 0.99251 & 0.36442 & 0.00749 & 0.57842 & 0.98524 \\
\hline 7 & 0.67392 & 0.99979 & 0.32608 & 0.00021 & 0.60527 & 0.99958 \\
\hline 8 & 0.68850 & 0.99464 & 0.31150 & 0.00536 & 0.61614 & 0.98940 \\
\hline 9 & 0.54470 & 0.97378 & 0.45530 & 0.02622 & 0.52339 & 0.95018 \\
\hline 10 & 0.06572 & 0.26454 & 0.93428 & 0.73546 & 0.34861 & 0.40471 \\
\hline 11 & 0.12514 & 0.95759 & 0.87486 & 0.04241 & 0.36367 & 0.92181 \\
\hline 12 & 0.66436 & 0.96410 & 0.33564 & 0.03590 & 0.59834 & 0.93300 \\
\hline 13 & 0.24642 & 0.97784 & 0.75358 & 0.02216 & 0.39886 & 0.95756 \\
\hline 14 & 0.58172 & 0.89947 & 0.41828 & 0.10053 & 0.54450 & 0.83260 \\
\hline 15 & 0.93084 & 1.00000 & 0.06916 & 0.00000 & 0.87849 & 1.00000 \\
\hline 16 & 0.35919 & 0.59787 & 0.64081 & 0.40213 & 0.43829 & 0.55425 \\
\hline 17 & 0.78295 & 0.98520 & 0.21705 & 0.01480 & 0.69731 & 0.97126 \\
\hline 18 & 0.78533 & 0.99560 & 0.21467 & 0.00440 & 0.69963 & 0.99128 \\
\hline 19 & 0.90916 & 0.99305 & 0.09084 & 0.00695 & 0.84625 & 0.98630 \\
\hline 20 & 0.44128 & 0.92643 & 0.55872 & 0.07357 & 0.47227 & 0.87173 \\
\hline 21 & 0.82108 & 0.74411 & 0.17892 & 0.25589 & 0.73647 & 0.66147 \\
\hline 22 & 0.53675 & 0.89303 & 0.46325 & 0.10697 & 0.51908 & 0.82376 \\
\hline 23 & 0.00000 & 0.77126 & 1.00000 & 0.22874 & 0.33333 & 0.68612 \\
\hline 24 & 0.79843 & 0.99601 & 0.20157 & 0.00399 & 0.71268 & 0.99208 \\
\hline 25 & 0.63069 & 0.88255 & 0.36931 & 0.11745 & 0.57517 & 0.80978 \\
\hline 26 & 0.56234 & 0.99721 & 0.43766 & 0.00279 & 0.53324 & 0.99446 \\
\hline 27 & 0.55345 & 0.93913 & 0.44655 & 0.06087 & 0.52824 & 0.89148 \\
\hline
\end{tabular}

relational grade has to be maximized so higher the better criterion is used to calculate the $S / N$ ratio, expressed as:

$$
\text { higher the better }=-10 \log \left(\frac{1}{n} \sum \frac{1}{y^{2}}\right),
$$

where $y$ is the observed data and $\mathrm{n}$ is the number of observations. Since the experimental design is orthogonal, it is then possible to separate out the effect of each coating parameter at different levels. The mean grey relational grade for each level of the factors A-D is summarized in Table 7. In addition, the total mean grey relational grade for the 27 experiments is also calculated and listed in Table 7. All the calculations are performed using Minitab [21]. The response table shows the average of the selected characteristic for each level of the factors. The response table includes ranks based on Delta statistics, which compare the relative magnitude of effects. The Delta statistic is the highest average for each factor minus the lowest average for the same. Ranks are assigned based on Delta values; rank 1 is assigned to the highest Delta value, rank 2 to the second highest Delta value, and so on. The corresponding main effects and interaction effects plots between the process parameters are also shown in Figures 2 and 3, respectively. In the main effects plot if the line for particular parameter is near horizontal, then the parameter has no significant effect. On the other hand, a parameter for which the line has the highest inclination will have the most significant effect. It is very much clear from the main effects plot that parameter C (concentration of tungsten source solution) is the most significant parameter while parameter $\mathrm{D}$ (annealing temperature) also has significant effect. So far as the interaction plots are concerned, estimating an interaction means determining the nonparallelism of parameter effects. Thus, if the lines on the interaction plots are nonparallel, interaction occurs and if the lines cross, strong interactions occur between parameters. From Figure 3 it can be seen that there is strong interaction between the parameters $\mathrm{A}$ and $\mathrm{C}$. Thus from the present analysis it is clear that the concentration of tungsten source solution (C) is the most influencing parameter for corrosion characteristics of Ni-P-W coatings. The optimal process parameter combination is the one that yields maximum mean $S / N$ ratio is found to be $A 3 B 3 C 3 D 3$.

5.3. Analysis of Variance (ANOVA). ANOVA is a statistical technique which can provide some important conclusions 


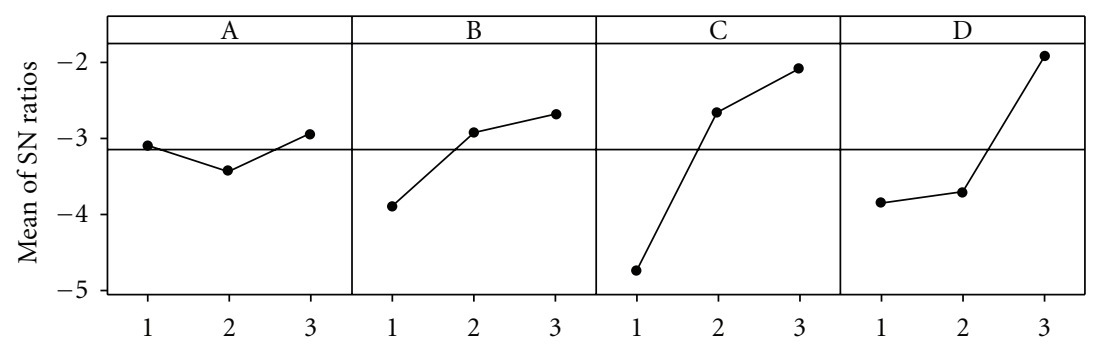

Figure 2: Main effect plot for mean $S / N$ ratio.

TABLE 6: Grey relational grade and its order.

\begin{tabular}{lcc}
\hline Sl. no. & Grade & Order \\
\hline 1 & 0.355353 & 27 \\
2 & 0.81204 & 7 \\
3 & 0.768406 & 11 \\
4 & 0.484362 & 25 \\
5 & 0.995587 & 1 \\
6 & 0.781829 & 10 \\
7 & 0.802424 & 9 \\
8 & 0.802772 & 8 \\
9 & 0.736788 & 14 \\
10 & 0.376657 & 26 \\
11 & 0.642741 & 22 \\
12 & 0.765673 & 12 \\
13 & 0.678207 & 19 \\
14 & 0.688549 & 18 \\
15 & 0.939243 & 2 \\
16 & 0.496266 & 24 \\
17 & 0.834282 & 6 \\
18 & 0.845456 & 5 \\
19 & 0.916275 & 3 \\
20 & 0.671999 & 20 \\
21 & 0.69897 & 16 \\
22 & 0.67142 & 21 \\
23 & 0.509726 & 23 \\
24 & 0.85238 & 4 \\
25 & 0.692476 & 17 \\
26 & 0.76385 & 15 \\
27 & 0.709857 & \\
\hline & & \\
\hline
\end{tabular}

TABLE 7: Mean response table for grey relational grade.

\begin{tabular}{lcccc}
\hline Level & $\mathrm{A}$ & $\mathrm{B}$ & $\mathrm{C}$ & $\mathrm{D}$ \\
\hline 1 & 0.7266 & 0.6676 & 0.6082 & 0.6604 \\
2 & 0.6963 & 0.7335 & 0.7468 & 0.6761 \\
3 & 0.7208 & 0.7427 & 0.7887 & 0.8073 \\
Delta & 0.0303 & 0.0751 & 0.1806 & 0.1468 \\
Rank & 4 & 3 & 1 & 2 \\
\hline \multicolumn{5}{l}{ Total mean grey relational grade $=0.714583$} \\
\hline
\end{tabular}

based on analysis of the experimental data. This method is very useful for revealing the level of significance of the influencing factor(s) or interaction of factors on a particular response. It separates the total variability of the response into contributions of each of the factors and the error.
TABle 8: ANOVA table.

\begin{tabular}{lccccc}
\hline Source & DF & SS & MS & $F$-ratio & \% contribution \\
\hline $\mathrm{A}$ & 2 & 0.00464 & 0.00232 & 0.22 & 0.71 \\
$\mathrm{~B}$ & 2 & 0.03021 & 0.01511 & 1.42 & 4.61 \\
$\mathrm{C}$ & 2 & 0.16078 & 0.08039 & $7.58^{*}$ & 24.51 \\
$\mathrm{D}$ & 2 & 0.11706 & 0.05853 & $5.52^{*}$ & 17.85 \\
$\mathrm{~A} * \mathrm{~B}$ & 4 & 0.06039 & 0.0151 & 1.42 & 9.21 \\
$\mathrm{~A} * \mathrm{C}$ & 4 & 0.19411 & 0.04853 & $4.57^{*}$ & 29.59 \\
$\mathrm{~B} * \mathrm{C}$ & 4 & 0.0251 & 0.00627 & 0.59 & 3.83 \\
Error & 6 & 0.06367 & 0.01061 & & 9.71 \\
\hline Total & 26 & 0.65596 & & & 100.00 \\
\hline
\end{tabular}

* Significant at $95 \%$ confidence level $\left(F_{2,6,0.05}=5.14\right.$ and $\left.F_{4,6,0.05}=4.53\right)$.

Using Minitab [21] ANOVA is performed to determine which parameter and interaction significantly affect the performance characteristics. Table 8 shows the ANOVA result for potentiodynamic behaviour of EN coatings. ANOVA calculates the F-ratio, which is the ratio between the regression mean square and the mean square error. The Fratio, also called the variance ratio, is the ratio of variance due to the effect of a factor and variance due to the error term. This ratio is used to measure the significance of the parameters under investigation with respect to the variance of all the terms included in the error term at the desired significance level, $\alpha$. If the calculated value of the F-ratio is higher than the tabulated value of the F-ratio, then the factor is significant at a desired $\alpha$ level. In general, when the $\mathrm{F}$ value increases, the significance of the parameter also increases. The ANOVA table shows the percentage contribution of each parameter. It is seen that parameter C, that is, concentration of tungsten source solution, has the most significant influence on potentiodynamic behaviour at the confidence level of $95 \%$ within the specific test range. The annealing temperature (D) is also significant at the same confidence level. Among the interactions the interaction of parameters between A and C has significant contribution. This type of analysis is not available in the literature and will be useful for Ni-P-W coating deposition with an objective of optimum corrosion behaviour within the particular range of process parameters.

5.4. Validation Test. After obtaining the optimal level of coating process parameters, the final step is to predict and verify the improvement of the performance characteristic using the optimal level of the process parameters. The 
TABLE 9: Results of confirmation test.

\begin{tabular}{|c|c|c|c|}
\hline & \multirow{2}{*}{ Initial parameter level } & \multicolumn{2}{|c|}{ Optimal parameter combination } \\
\hline & & Prediction & Experimentation \\
\hline Level & $\mathrm{A} 2 \mathrm{~B} 2 \mathrm{C} 2 \mathrm{D} 2$ & \multicolumn{2}{|c|}{ A3B3C3D3 } \\
\hline $\mathrm{E}_{\text {corr }}(\mathrm{mV}$ versus SCE $)$ & -354.89 & & -278.71 \\
\hline $\mathrm{I}_{\text {corr }}\left(\mu \mathrm{A} / \mathrm{cm}^{2}\right)$ & 0.9031 & & 0.080 \\
\hline Grade & 0.662402 & 0.881417 & 0.916275 \\
\hline
\end{tabular}

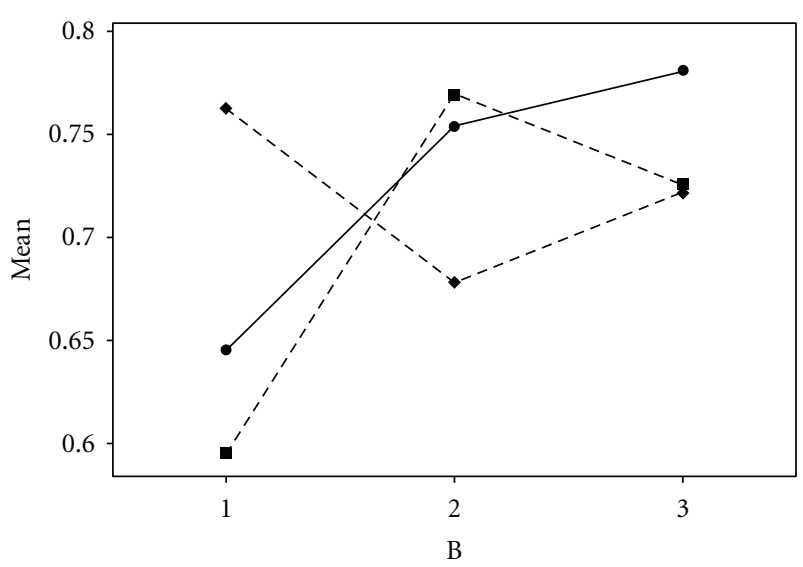

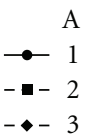

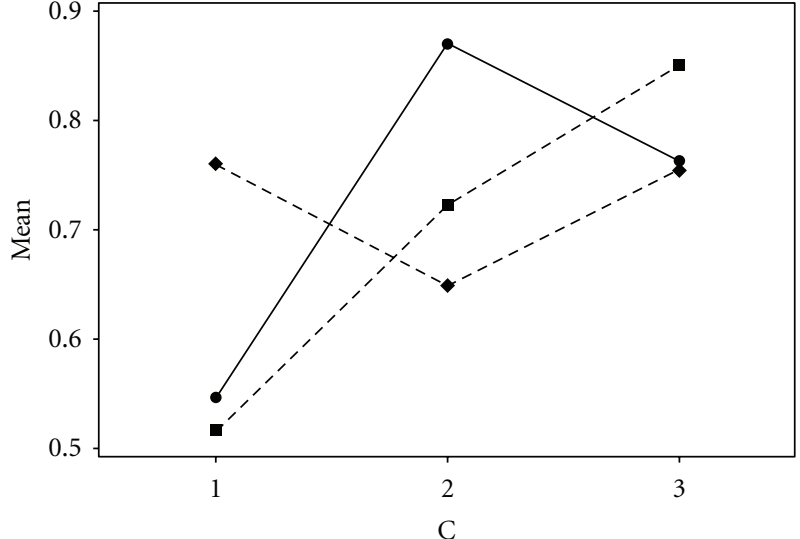

A

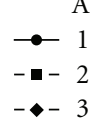

(b) Interaction Plot A versus C

(a) Interaction Plot A versus B

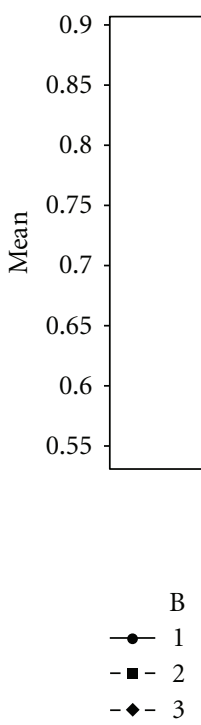

(c) Interaction Plot B versus C

Figure 3: Interaction plots, (a) between A\&B, (b) between A\&C, and (c) between B\&C.

estimated grey relational grade, $\hat{\eta}$, using the optimal level of the process parameters can be calculated as:

$$
\hat{\eta}=\eta_{m}+\sum_{i=1}^{0}\left(\bar{\eta}_{i}-\eta_{m}\right)
$$

where $\eta_{m}$ is the total mean grey relational grade, $\bar{\eta}_{i}$ is the mean grey relational grade at the optimal process parameter level and 0 is the number of the main design process parameters that significantly affect the potentiodynamic characteristics of Ni-P-W coating. Table 9 shows the 


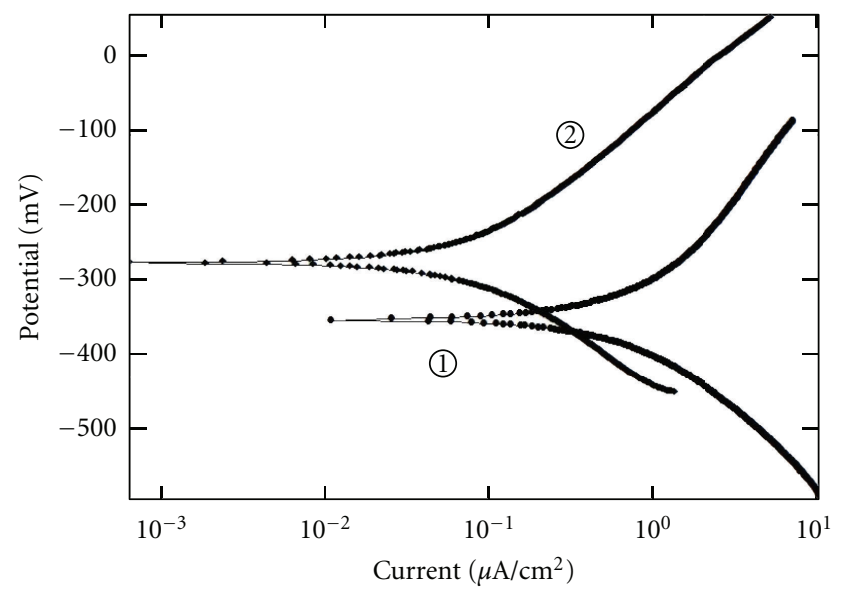

FIgUre 4: Polarization curves for coatings (1) Initial condition, (2) optimal condition.

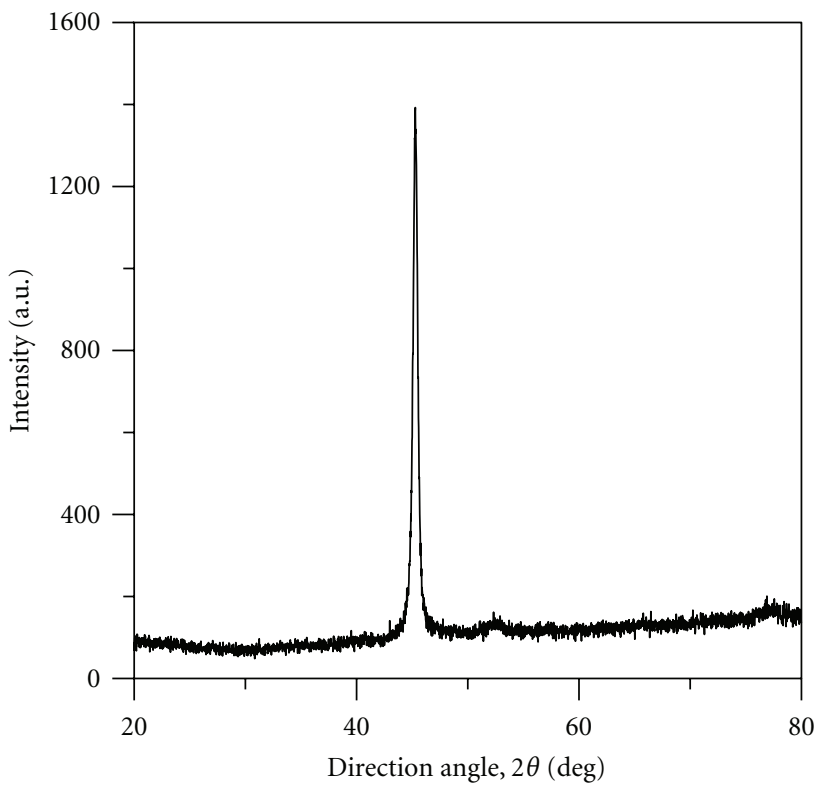

(a)

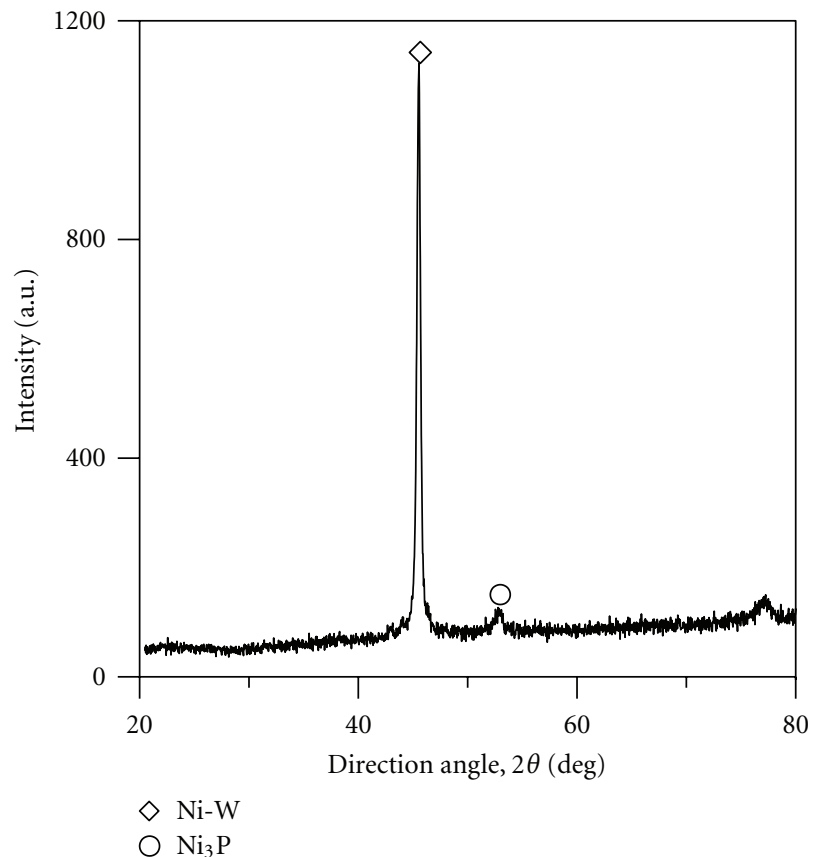

(b)

FIgURE 5: XRD plots of Ni-P-W coatings (a) as deposited, (b) heat treated at $500^{\circ} \mathrm{C}$.

comparison of the estimated grey relational grade with the actual grey relational grade using the optimal parameters. The improvement of grey relational grade from initial to optimal condition is 0.253873 , which is about $35 \%$ of the mean grey relational grade and is a significant improvement. The polarization curves for the coatings developed at initial condition and at optimal condition are shown in Figure 4.

5.5. Characterization of the Coating. An X-ray diffraction (XRD) analyzer (Rigaku, Miniflex) is used for identification of compounds in the EN coatings both before and after heat treatment. Figure 5 shows the XRD plots of as deposited and heat treated conditions. From the figure it is evident that as deposited condition the phase is mostly amorphous but there exist a crystalline peak so it may be attributed that the coated surface has a mixture of amorphous and crystalline phase. After heat treatment the some of the peaks are broaden and produce crystalline phase. After heating at $500^{\circ} \mathrm{C}$ for 1 hour the major peaks of $\mathrm{Ni}-\mathrm{W}$ and $\mathrm{Ni}_{3} \mathrm{P}$ are obtained. Energy dispersive X-ray analysis (EDAX Corporation) is performed to determine the composition of the coating in terms of the weight percentages of nickel phosphorous and tungsten. The EDX analysis is done on the coatings developed from the bath consisting of different concentrations of sodium tungstate (tungsten ions) in order to capture the range of tungsten content in the coatings. It is found that the coating consists of $88 \%$ nickel, $8 \%$ phosphorous, and $4 \%$ tungsten. Figure 6 shows the EDX spectra of the coated surface. Figure 7 shows the SEM micrograph of as deposited and heat treated $\left(400^{\circ} \mathrm{C}, 500^{\circ} \mathrm{C}\right.$, and $\left.600^{\circ} \mathrm{C}\right) \mathrm{Ni}-\mathrm{P}-\mathrm{W}$ coated 


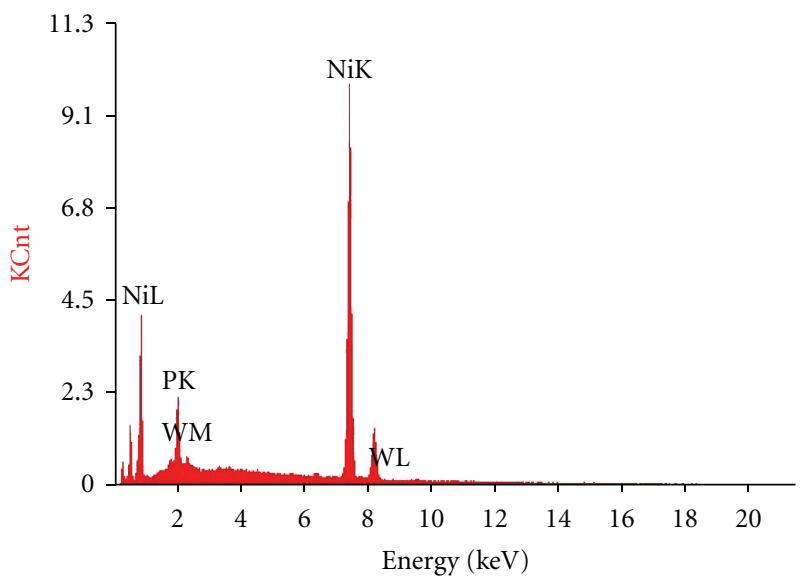

FIgURE 6: EDX spectra of Ni-P-W coated specimen.

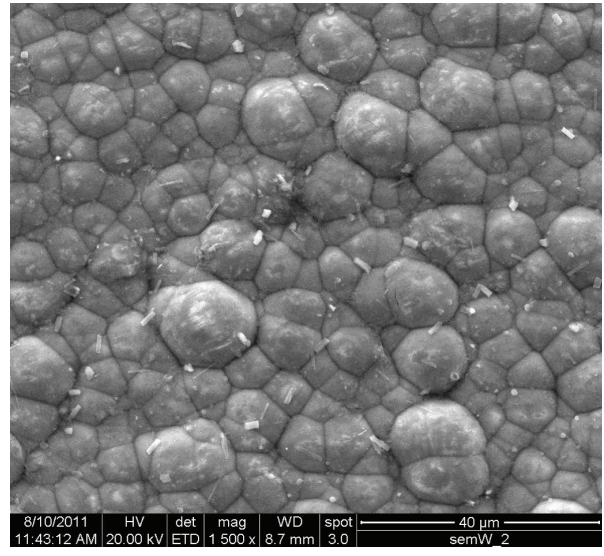

(a)

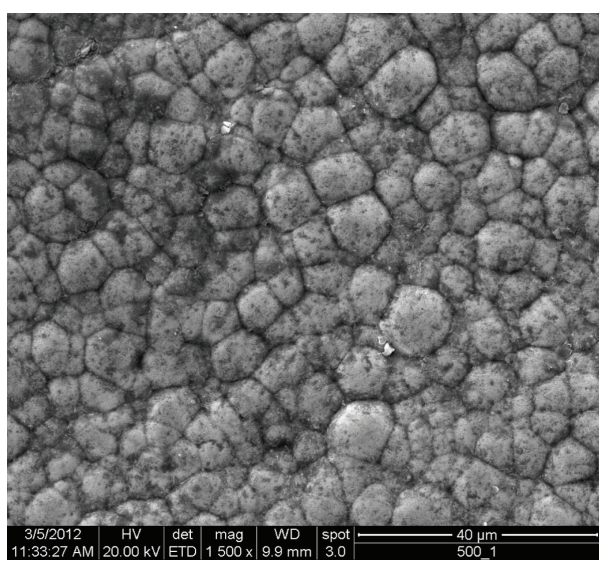

(c)

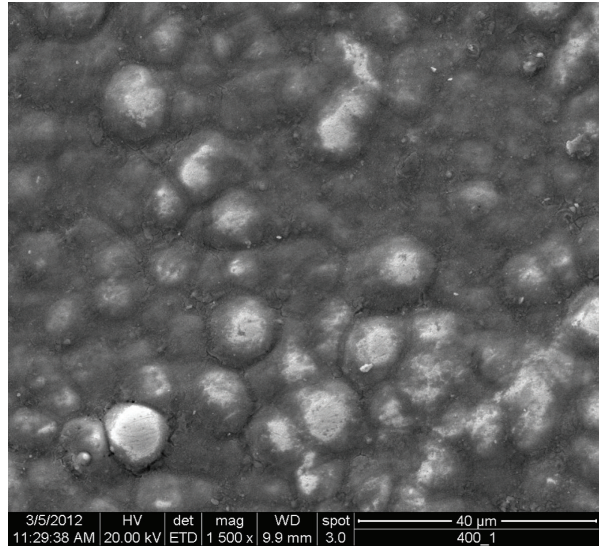

(b)

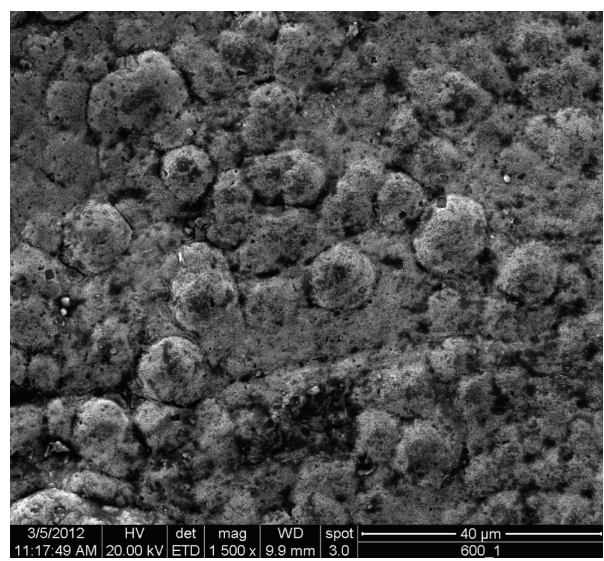

(d)

Figure 7: SEM image of coatings (a) as deposited, (b) annealed at $400^{\circ} \mathrm{C}$, (c) annealed at $500^{\circ} \mathrm{C}$, (d) annealed at $600^{\circ} \mathrm{C}$.

surface. It is clear that the deposit has globular like shape without any porosity in as deposited condition. When it is heat treated at $500^{\circ} \mathrm{C}$ the globules become more compact and produce a dense structure resulting harder deposit. With further heating at $600^{\circ} \mathrm{C}$ the size of the globule increases and transformed in to coarse grained structure. Corrosion mechanism of the amorphous electroless Ni-P-W coatings treated by furnace-annealing can be considered as a result of combined effects from porosity, phase constitutes and proportion, residual stress, and grain sizes. However, each factor plays a different role in different cases.

\section{Conclusion}

Taguchi orthogonal array coupled with grey relational analysis is employed to find the optimum coating parameter 
combination for maximum corrosion resistance of electroless Ni-P-W coating. The coating composition is studied by EDX analysis. The microstructural aspects and crystallization behaviour is studied with the help of SEM and XRD analysis. The following conclusions can be drawn based on the experimental results obtained which clearly indicate the possibility of significant improvement of corrosion resistance of electrolessly deposited Ni-P-W alloy coating.

(1) The concentration of tungsten source and annealing temperature has significant influence on the potentiodynamic behaviour of this coating.

(2) The interaction between nickel source and tungsten source has the maximum significance among the interactions.

(3) The corrosion resistance of the coating improves at an annealing temperature higher than $400^{\circ} \mathrm{C}$.

(4) The optimum combination of coating parameters for maximum corrosion resistance is found as: nickel concentration $30 \mathrm{~g} / \mathrm{L}$, reducing agent concentration $20 \mathrm{~g} / \mathrm{L}$, tungsten concentration $25 \mathrm{~g} / \mathrm{L}$, and annealing temperature $600^{\circ} \mathrm{C}$.

\section{References}

[1] T. S. N. S. Narayanan, K. Krishnaveni, and S. K. Seshadri, "Electroless Ni-P/Ni-B duplex coatings: preparation and evaluation of microhardness, wear and corrosion resistance," Materials Chemistry and Physics, vol. 82, no. 3, pp. 771-779, 2003.

[2] P. Sahoo and S. K. Das, "Tribology of electroless nickel coatings-a review," Materials and Design, vol. 32, no. 4, pp. 1760-1775, 2011.

[3] R. C. Agarwala and V. Agarwala, "Electroless alloy/composite coatings: a review," Sadhana, vol. 28, no. 3-4, pp. 475-493, 2003.

[4] S. K. Das and P. Sahoo, "Study of potentiodynamic polarization behaviour of electroless $\mathrm{Ni}-\mathrm{B}$ coatings and optimization using Taguchi method and Grey relational analysis," Journal of Minerals \& Materials Characterization \& Engineering, vol. 10, no. 14, pp. 1307-1327, 2011.

[5] W. Riedel, Eletroless Nickel Plating, Finishing Publications Ltd, Stevenage, Hertfordshire, UK, 1991.

[6] A. Farzaneh, M. Ehteshamzadeh, and M. Mohammadi, "Corrosion performance of the electroless $\mathrm{Ni}-\mathrm{P}$ coatings prepared in different conditions and optimized by the Taguchi method," Journal of Applied Electrochemistry, vol. 41, no. 1, pp. 19-27, 2011.

[7] A. S. Hamdy, M. A. Shoeib, H. Hady, and O. F. Abdel Salam, "Corrosion behavior of electroless Ni-P alloy coatings containing tungsten or nano-scattered alumina composite in $3.5 \% \mathrm{NaCl}$ solution," Surface and Coatings Technology, vol. 202, no. 1, pp. 162-171, 2007.

[8] P. Nash, Phase Diagrams of Binary Nickel Alloys, ASM International,, 1991.

[9] Y. Y. Tsai, F. B. Wu, Y. I. Chen, P. J. Peng, J. G. Duh, and S. Y. Tsai, "Thermal stability and mechanical properties of Ni-WP electroless deposits," Surface and Coatings Technology, vol. 146-147, pp. 502-507, 2001.
[10] Q. Zhao, Y. Liu, H. Müller-Steinhagen, and G. Liu, "Graded Ni-P-PTFE coatings and their potential applications," Surface and Coatings Technology, vol. 155, no. 2-3, pp. 279-284, 2002.

[11] F. B. Wu, Y. I. Chen, P. J. Peng, Y. Y. Tsai, and J. G. Duh, "Fabrication, thermal stability and microhardness of sputtered Ni-P-W coating," Surface and Coatings Technology, vol. 150, no. 2-3, pp. 232-238, 2002.

[12] M. Palaniappa and S. K. Seshadri, "Friction and wear behavior of electroless Ni-P and Ni-W-P alloy coatings," Wear, vol. 265, no. 5-6, pp. 735-740, 2008.

[13] H. Liu, F. Viejo, R. X. Guo, S. Glenday, and Z. Liu, "Microstructure and corrosion performance of laser-annealed electroless Ni-W-P coatings," Surface and Coatings Technology, vol. 204, no. 9-10, pp. 1549-1555, 2010.

[14] G. Lu and G. Zangari, "Corrosion resistance of ternary NiP based alloys in sulfuric acid solutions," Electrochimica Acta, vol. 47, no. 18, pp. 2969-2979, 2002.

[15] Y. Gao, Z. J. Zheng, M. Zhu, and C. P. Luo, "Corrosion resistance of electrolessly deposited Ni-P and Ni-W-P alloys with various structures," Materials Science and Engineering A, vol. 381, no. 1-2, pp. 98-103, 2004.

[16] K. N. Srinivasan, R. Meenakshi, A. Santhi, P. R. Thangavelu, and S. John, "Studies on development of electroless Ni-B bath for corrosion resistance and wear resistance applications," Surface Engineering, vol. 26, no. 3, pp. 153-158, 2010.

[17] T. S. N. S. Narayanan and S. K. Seshadri, "Formation and characterization of borohydride reduced electroless nickel deposits," Journal of Alloys and Compounds, vol. 365, no. 1-2, pp. 197-205, 2004.

[18] C. T. Dervos, J. Novakovic, and P. Vassiliou, "Vacuum heat treatment of electroless Ni-B coatings," Materials Letters, vol. 58, no. 5, pp. 619-623, 2004.

[19] R. K. Roy, A Primer on the Taguchi Method, Society of Manufacturing Engineers, Dearborn, Mich, USA, 1990.

[20] J. Deng, "Introduction to grey system," Journal of Grey System, vol. 1, no. 1, pp. 1-24, 1989.

[21] MINITAB Inc., Minitab User Manual, Making Data Analysis Easier, MINITAB Inc., State College, Pa, USA, 2001. 

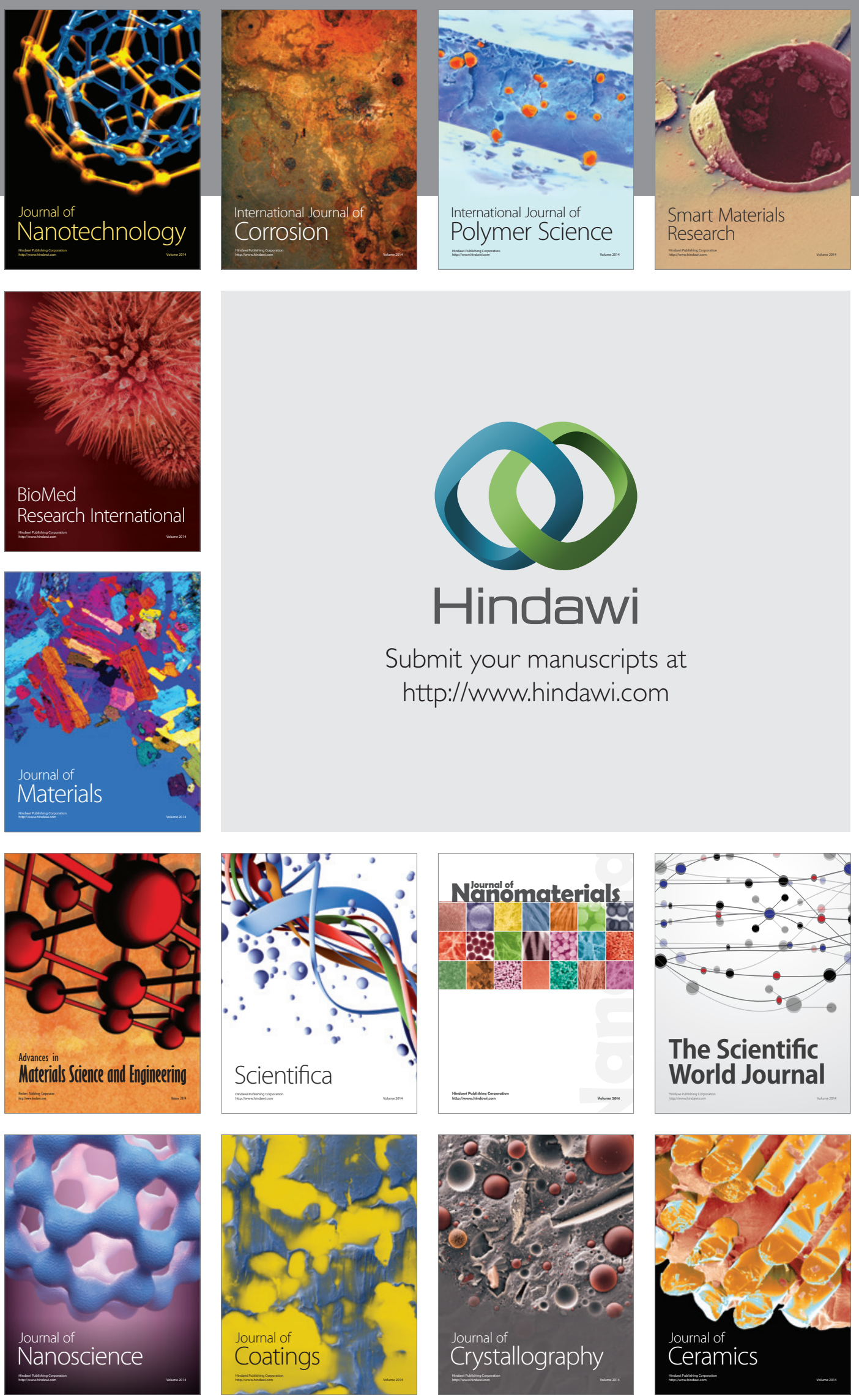

The Scientific World Journal

Submit your manuscripts at

http://www.hindawi.com

\section{World Journal}

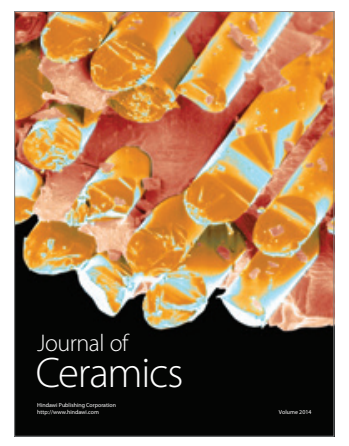

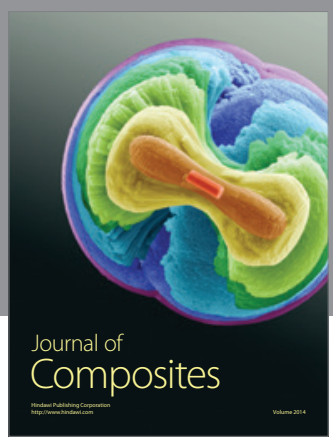
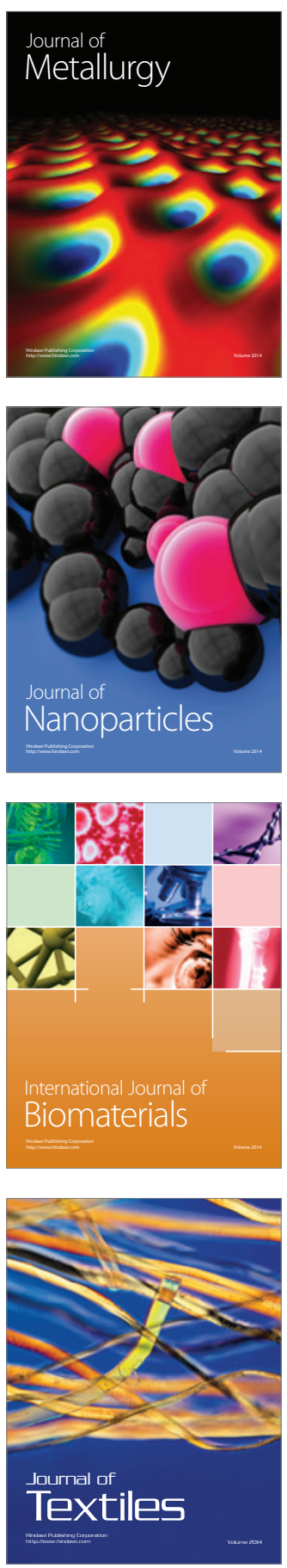